\begin{tabular}{|c|c|c|}
\hline \multirow[b]{2}{*}{ EYCEI I ENT } & Int.J.Curr.Microbiol.App.Sci (2021) 10(08): 247-257 & \\
\hline & $\begin{array}{l}\text { International Journal of Current Microbiology and Applied Sciences } \\
\text { ISSN: 2319-7706 Volume } 10 \text { Number } 08 \text { (2021) } \\
\text { Journal homepage: } \underline{\text { http://www.ijcmas.com }}\end{array}$ & $\$ 90$ \\
\hline PUBLISHERS & & muww.ijcmas.com \\
\hline
\end{tabular}

Original Research Article

https://doi.org/10.20546/ijcmas.2021.1008.029

\title{
Runoff Modeling using ANN-based Generalized Feed Forward (GFF) and Multi Linear Regression (MLR) Technique for Narmada River Basin, Gujarat
}

\author{
Shrisht Suman ${ }^{1}$, Vikram Singh ${ }^{1}$, Tushar Rathod ${ }^{1 *}$ and C. John Wesley ${ }^{2}$ \\ ${ }^{1}$ Department of Soil and Water conservation Engineering, VIAET, SHUATS, Prayagraj, India \\ ${ }^{2}$ Center for Geospatial Technology, VIAET, SHUATS, Prayagraj, India \\ *Corresponding author
}

Keywords

Water, Agriculture, renewable resource, rainfall intensity, duration, initial soil moisture

Article Info

Accepted:

15 July 2021

Available Online:

10 August 2021

\section{A B S T R A C T}

Runoff prediction is one of the most important topics in water resources planning, development and management on a sustainable basis. The Generalized Feed Forward (GFF) and Multiple Linear Regression (MLR). This study was undertaken to develop and evaluate the applicability of the GFF and MLR models by way of training and testing of developed models during monsoon period (June to September) for Narmada River Basin in Chota Udaipur district of Gujarat state of India. The daily data of rainfall, runoff, minimum \& maximum temperature and wind speed were used in the study for monsoon season. The daily data were split into two sets: a training data set from 2004 to 2008 and a testing data set from 2009 to 2010 for Narmada river basin. The input pairs in the training data set were applied to the network of a selected architecture and training was performed using a back propagation algorithm for GFF models. A number of networks were constructed and each of them was trained separately, and the best network was selected based on the accuracy of the predictions in the testing phase. The following statistical indices such as mean squared error (MSE), coefficient of efficiency (CE), coefficient of determination $\left(\mathrm{R}^{2}\right)$ and coefficient of correlation ( $r$ ) were applied to test the performance of the developed GFF and MLR models. The predicted suspended sediment using GFF models were found to be the best performing models for Narmada river basin. It was evident that MLR models fit very poorly for the dataset under study. The current day's runoff can be simulated using the data of minimum temperature \& wind speed (GFF-8).

\section{Introduction}

Water is the greatest resource for humanity. It not only helps in survival but also makes life comfortable and luxurious. Although water is a renewable resource, its availability in appropriate quality and quantity is under severe stress due to increase demand from various sectors. Agriculture is the largest user of water, which consume more than $80 \%$ of the exploitable water resources. Artificial Neural Network is an information processing 
paradigm that is inspired by the processing elements or neurons working in parallel to solve specific problems.

Various factors were responsible for causing variability in sediment load among all factors rainfall as well as stream flow was to significant factors which effect suspended load concentration (Jie and $\mathrm{Yu}, 2011$ ). The quality of runoff and sediment yield also depend on the rainfall intensity, duration, initial soil moisture, land use and land cover, slope of the watershed etc.

In many rivers, a major part of the sediment is transported in suspension. Recently, the importance of correct sediment prediction, especially in flood-prone areas, has increased significantly in water resources and environmental engineering. During the past few decades, a great deal of research has been devoted to the simulation and prediction of river sediment dynamics.

The daily suspended sediment load $(\mathrm{S})$ process is among one of the most complex nonlinear hydrological and environmental phenomena to comprehend, because it usually involves a number of interconnected elements. Studies have been conducted to reduce the complexities of the problem by developing practical techniques that do not require much algorithm and theory.

In this way, classical models such as multi linear regression (MLR) and sediment rating curve (SRC) are widely used for suspended sediment modeling (Kisi 2005). The last decade has seen a tremendous growth in interest in the application of artificial neural networks (ANNs) to water resources and environmental problems. The ANN, as the name implies, employs the model construction of a neural network, a very powerful computational algorithm which is used to simulate complex nonlinear relationships, especially in situations where the explicit form of the relation between the variables involved is unknown.

River suspended sediment load is a principal parameter in reservoir management and can serve as an index to understand the status of soil erosion and ecological environment in a watershed. The rainfall-sediment yield process is extremely complex, non-linear, dynamic, and fragmented due to spatial variability of watershed geomorphologic characteristics, spatial/temporal variability of rainfall and involvement of other physical processes.

Therefore, predicting sediment yield process in river basins requires a non-linear modeling approach such as ANN which can capture complex temporal variations within time series data. The ANN is a powerful soft computational technique which has been widely used in many areas of water resource management and environmental sciences.

In order to predict accurate results of rainfall forecast, various models have been developed. With the advent of machine learning technologies, many researchers are trying to make predictions using the ANN method in the field of hydrology, (Mislan et al., 2015) have conducted research with ANN monthly rainfall prediction in Tengarrong station, East Kalimantan-Indonesia using back propagation neural network (BPNN) algorithm.(Kumar et al., 2012) have conducted research with ANN rainfall prediction in Udupi district of Karnataka, India.

The results of these researches have revealed that accurate prediction of rainfall was obtained using ANN. In this study, the runoff models have been developed using GFF \& MLR technique for narmada river basin Gujarat. Appropriate input variables for these models were selected on statistical indices such as Mean Square Error (MSE), 
Coefficient of determination, coefficient of correlation \& coefficient of efficiency.

\section{Materials and Methods}

\section{Location of Study Area}

The area selected for the study is Chhota Udaipur a city and municipality in Chhota Udaipur district in the state of Gujarat, India. The population is 27,166 (2001). It is located at $22^{\circ} 18^{\prime} 20^{\prime \prime} \mathrm{N}, 74^{\circ} 0^{\prime} 50^{\prime \prime} \mathrm{E}$. Its elevation is 492 ft. Chhota Udaipur has a Semi-Arid climate. Its average annual temperature is $12-43^{\circ} \mathrm{C}$.

\section{Area detail and climatic characteristics}

Out of total land of $3,087 \mathrm{~km}^{2}, 34,606$ hectares geographical area, 165,430 hectare were cultivable area and 75,304 hectare were forest area. The agricultural land use is 169,088 hectare were cotton, maize, pigeon pea, paddy, blackgram, soybean, castor, wheat etc. mainly produced. There are medium black soil, hilly light soil, sandy loam soil which is suitable for crops.

Irrigation is done mainly by canals, tanks, open wells, bore wells and other water sources. There were 58,816 hectare for gross irrigated area and 165,430 for rainfed area.

\section{Materials and Methods}

In this study, the soft computing techniques such as Generalized Feed Forward (GFF) based ANN and statistical multiple linear regression (MLR) have been developed for simulating the rainfall in Satna district. The methodology of developing the GFF and MLR models along with training and testing of developed models, the NeuroSolution 5.0 software and Microsoft Excel were used in analysis and the performance evaluation indices for developed models are also described in this section.

\section{Artificial neural network}

An artificial neural network (ANNs), a systems theoretic method, is a promising tool for modelling hydrological processes (Ghumman et al., 2017). ANNs with one hidden layer are commonly used in hydrological modelling (Dawson and Wilby, 2001) as one hidden layer with non-linear activation function is sufficient to take care of the non-linearity of the hydrological process. The neural network is created for two different phases in the most general sense. The first is the training phase and the second is the testing (simulation) phase (Tapkin et al., 2006).

\section{Generalized Feed Forward (GFF)}

The type of network chosen for the study was a Generalized Feed-forward Network (GFF). A GFF is a kind of feed- forward Neural Network (FNN) in which the neurons in one layer are not connected to the neurons of the next layer, but also to all those neurons of all the forward layers as shown in Fig.2. This type of network can usually be the trained more quickly than non-generalized FNNs, as they present a larger number of connections. The best-known and simplest training algorithm for feed-forward networks is Backpropagation (Rumelhart et al., 1986). Back Propagation training algorithm is in general used algorithm for multi hidden layer to the hidden layer(s) and then it goes to output with a selected accuracy. The network weights are optimized by using least square method along with the generalized delta rule.

\section{Generalized Feed Forward (GFF) Architecture}

\section{Layers}

GFFs are usually organized into something called layers. As discussed above the neural networks has layers, the generalized artificial 
neural network consists of an input layer, some number (possibly zero) of hidden layers, and an output layer. In case of a single-layer perceptron, there are no hidden layers, so that total number of layers is two.

\section{Single Layer}

The simplest type of feed forward neural network is the perceptron, a feed an output layer. The output units are computed directly from the sum of the product of their weights with the corresponding input units, plus some bias.

\section{Multiple Layers}

Differently from networks belonging to the previous architecture, feed forward networks with multiple layers are composed of one or more hidden neural layers. They are employed in the solution of diverse problems, like those related to function approximation, pattern classification, system identification, process control, optimization, robotics and so on.

\section{Activation Function}

Activation function is really important for an Artificial Neural Network to learn and make sense of something really complicated and non-linear complex functional mapping between the inputs and response variable.

If we do not apply an activation function then the output signal would simply be a simple linear function. A linear function is just a polynomial of one degree.

The Hyperbolic tangent (Tanh) is normally employed as hidden and hyperbolic tangent (Tanh) function to each neuron in the layer, thus outputting values within the range -1 to +1 for each neuron (Litta et al., 2013). This hyperbolic tangent (tanh) function is expressed as: $\tanh (x)=\frac{\sinh (x)}{\cosh (x)}$

\section{Multiple Linear Regression (MLR)}

MLR is the simplest, statistical and welldeveloped representation of the time-invariant relationship between an input function and corresponding output function (Chavan and Ukrande, 2017). One of the classical problems in statistical analysis is to find a suitable relationship between a response variable and a set of regression variables. Regression analysis is commonly used to describe quantitative relationships between a response variable and one or more explanatory variables.

Multiple Linear Regression (MLR) is simply an extended form of Simple regression in which two or more variables are independent variables are used and can be expressed as (Kumar and Malik, 2015):

$Y=\alpha+\beta_{1} X_{1}+\beta_{2} X_{2}+\ldots \ldots \ldots \ldots \beta_{p} X_{p}$

Where,

$\mathrm{Y}=$ Dependent variable;

$\alpha=$ Constant or intercept;

$\beta 1=$ Slope $($ Beta coefficient $)$ for $\mathrm{X} 1$;

$\mathrm{X} 1=$ First independent variable that is explaining the variance in $\mathrm{Y}$;

$\beta 2=$ Slope (Beta coefficient $)$ for X2;

$\mathrm{X} 2=$ Second independent variable that is explaining the variance in $\mathrm{Y}$;

$p=$ Number of independent variables;

$\beta p=$ Slope coefficient for $\mathrm{Xp}$; 
$\mathrm{Xp}=\mathrm{pth}$ independent variable explaining the variance in $\mathrm{Y}$.

In spite of their obvious success in many applications, MLRs present multi-collinearity when employed with climatic variables. In this regard, the parameter estimation errors can be incorrectly interpreted (Mendes et al., 2016).

\section{Formulation of GFF and MLR models}

Identification of input and output variables is the first step for developing the GFF and MLR models. The last 10 years daily meteorological and hydrological data were used to develop the models. The measured meteorological and hydrological data were split into two sets: a training data set from 2004 to 2011 and a testing data set from 2012 to 2013 for Satna district. Out of 1220 datasets, 976 (80\%) were used for training and 244 (20\%) were used for testing in ANN-based GFF technique.

The various input-output combinations of GFF and MLR models for the study areas are listed in Tables 1 and 2.

\section{Training and testing of GFF and MLR models}

The daily data of rainfall, and meteorological data (temperature and humidity) on daily basis were split into two sets: a training data set from 2004 to 2008 and a testing data set from 2009 to 2010. The input pairs in the training data set were applied to the network of a selected architecture and training was performed using a back propagation algorithm for GFF (Table 3).

\section{Results and Discussion}

The development and application of GFF models and Multi Linear Regression for daily runoff forecasting during the year (2004-2010) for Chhota Udaipur district of Gujarat, India, have been discussed in this chapter. The daily meteorological data i.e. rainfall, minimum and maximum temperature, wind speed and discharge for the year 2004 to 2008 were used during the training of various model network and data of years 2009 to 2010 were used validation (testing) of the developed models.

The performance of models was evaluated qualitatively by visual observation and various statistical and hydrological indices viz. Mean square error (MSE), correlation coefficient (r) and coefficient of efficiency (CE).

The model having higher values of correlation coefficient and coefficient of efficiency and low value of mean square error is considered as the best fit model.

\section{Runoff modelling using GFF}

GFF models (Table 3) were used to simulate rainfall as output based on various input combinations of minimum and maximum temperature, wind speed and rainfall.GFF-8 (1-6-1), GFF-8 (1-4-1), GFF-8 (1-8-1), GFF10 (1-2-1), GFF-9 (1-2-1), GFF-14 (1-4-1), GFF-6 (1-6-1), GFF-11 (1-6-1), GFF-11 (1-41) and GFF-10 (1-4-1) were selected for further analysis and comparison based on the statistical indices, such as root mean squared error (RMSE), coefficient of efficiency (CE) and correlation coefficient (r).

The values of statistical indices for the selected GFF models during testing are presented in Tables 4 respectively.

As observed from Table 4 indicates that the MSE for the selected GFF models varied from 0.0002 to 0.0014 during testing. The $\mathrm{CE}$ values ranged from 0.1470 to 0.8920 for testing. The correlation coefficient $(r)$ values ranged from 0.7630 to 0.9910 for testing. 
Table.1 Input-output combination for GFF models for runoff prediction for Narmada basin at Chhota Udaipur

\begin{tabular}{|c|c|}
\hline Model No. & Input-Output Variables \\
\hline GFF-1 & $\mathrm{Q}_{\mathrm{t}}=f\left(\mathrm{~T}_{\min }\right)$ \\
\hline GFF-2 & $\mathrm{Q}_{\mathrm{t}}=f\left(\mathrm{~T}_{\max }\right)$ \\
\hline GFF-3 & $\mathrm{Q}_{\mathrm{t}}=f(\mathrm{Ws})$ \\
\hline GFF-4 & $\mathrm{Q}_{\mathrm{t}}=f(\mathrm{Rt})$ \\
\hline GFF-5 & $\mathrm{Q}_{\mathrm{t}}=f\left(\mathrm{~T}_{\min }, \mathrm{T}_{\max }\right)$ \\
\hline GFF-6 & $\mathrm{Q}_{\mathrm{t}}=f\left(\mathrm{~T}_{\min }, \mathrm{Ws}\right)$ \\
\hline GFF-7 & $\mathrm{Q}_{\mathrm{t}}=f\left(\mathrm{~T}_{\min }, \mathrm{R}_{\mathrm{t}}\right)$ \\
\hline GFF-8 & $\mathrm{Q}_{\mathrm{t}}=f\left(\mathrm{~T}_{\max }, \mathrm{Ws}\right)$ \\
\hline GFF-9 & $\mathrm{Q}_{\mathrm{t}}=f\left(\mathrm{~T}_{\max }, \mathrm{Rt}\right)$ \\
\hline GFF-10 & $\mathrm{Q}_{\mathrm{t}}=f(\mathrm{Ws}, \mathrm{Rt})$ \\
\hline GFF-11 & $\mathrm{Q}_{\mathrm{t}}=f\left(\mathrm{~T}_{\min }, \mathrm{T}_{\max }, \mathrm{Ws}\right)$ \\
\hline GFF-12 & $\mathrm{Q}_{\mathrm{t}}=f\left(\mathrm{~T}_{\min }, \mathrm{Ws}, \mathrm{Rt}\right)$ \\
\hline GFF-13 & $\mathrm{Q}_{\mathrm{t}}=f\left(\mathrm{~T}_{\max }, \mathrm{Ws}, \mathrm{Rt}\right)$ \\
\hline GFF-14 & $\mathrm{Q}_{\mathrm{t}}=f\left(\mathrm{~T}_{\min }, \mathrm{T}_{\max }, \mathrm{Rt}\right)$ \\
\hline GFF-15 & $\mathrm{Q}_{\mathrm{t}}=f\left(\mathrm{~T}_{\min }, \mathrm{T}_{\max }, \mathrm{Ws}, \mathrm{Rt}\right)$ \\
\hline
\end{tabular}

Table.2 Input-Output combination of MLR models for runoff prediction for Narmada basin at Chhota Udaipur

\begin{tabular}{|c|c|}
\hline Model No. & Input-Output Variables \\
\hline MLR-1 & $\mathrm{Q}_{\mathrm{t}}=e_{1}+\mathrm{g}_{1} \mathrm{~T}_{\min }$ \\
\hline MLR-2 & $\mathrm{Q}_{\mathrm{t}}=e_{2}+\mathrm{g}_{2} \mathrm{Tmax}$ \\
\hline MLR-3 & $\mathrm{Q}_{\mathrm{t}}=e_{3}+\mathrm{h} 1 \mathrm{Ws}$ \\
\hline MLR-4 & $\mathrm{Q}_{\mathrm{t}}=e_{4}+\mathrm{h} 2 \mathrm{Rt}$ \\
\hline MLR-5 & $\mathrm{Q}_{\mathrm{t}}=e_{5}+\mathrm{g}_{3} \mathrm{~T}_{\min }+\mathrm{g}_{3}, \mathrm{~T} \max$ \\
\hline MLR-6 & $\mathrm{Q}_{\mathrm{t}}=e_{6}+\mathrm{g}_{4} \mathrm{~T}_{\min }+\mathrm{h} 3 \mathrm{Ws}$ \\
\hline MLR-7 & $\mathrm{Q}_{\mathrm{t}}=e_{7}+\mathrm{g}_{5} \mathrm{~T}_{\min }+\mathrm{h} 4 \mathrm{Rt}$ \\
\hline MLR-8 & $\mathrm{Q}_{\mathrm{t}}=e_{8}+\mathrm{g}_{6} \mathrm{~T}_{\max }+\mathrm{h} 5 \mathrm{Ws}$ \\
\hline MLR-9 & $\mathrm{Q}_{\mathrm{t}}=e_{9}+\mathrm{g}_{7} \mathrm{~T}_{\max }+\mathrm{h} 6 \mathrm{Rt}$ \\
\hline MLR-10 & $\mathrm{Q}_{\mathrm{t}}=e_{10}+\mathrm{h} 7 \mathrm{Ws}+\mathrm{h} 8 \mathrm{Rt}$ \\
\hline MLR-11 & $\mathrm{Q}_{\mathrm{t}}=e_{11}+\mathrm{g}_{8} \mathrm{~T}_{\min }+\mathrm{g}_{9} \mathrm{~T}_{\max }+\mathrm{h} 9 \mathrm{Ws}$ \\
\hline MLR-12 & $\mathrm{Q}_{\mathrm{t}}=e_{12}+\mathrm{g}_{10} \mathrm{~T}_{\min }+\mathrm{h} 10 \mathrm{Ws}+\mathrm{h} 11 \mathrm{Rt}$ \\
\hline MLR-13 & $\mathrm{Q}_{\mathrm{t}}=e_{13}+\mathrm{h}_{6} \mathrm{~T}_{\max }+\mathrm{k} 7 \mathrm{Ws}+\mathrm{I} 6 \mathrm{Rt}$ \\
\hline MLR-14 & $\mathrm{Q}_{\mathrm{t}}=e_{14}+\mathrm{g}_{7} \mathrm{~T}_{\min }+\mathrm{h} 7 \mathrm{~T}_{\max }+\mathrm{I} 7 \mathrm{Rt}$ \\
\hline MLR-15 & $\mathrm{Q}_{\mathrm{t}}=e_{8}+\mathrm{g}_{8} \mathrm{~T}_{\min }+\mathrm{h} 8 \mathrm{~T}_{\max }+\mathrm{k} 8 \mathrm{Ws}+\mathrm{I} 8 \mathrm{Rt}$ \\
\hline
\end{tabular}

${ }^{*} \mathrm{e}_{\mathrm{i}}, \mathrm{g}_{\mathrm{i}}, \mathrm{g}_{\mathrm{i}}{ }_{\mathrm{i}}, \mathrm{h}_{\mathrm{i}}$ and $\mathrm{h}_{\mathrm{i}}$ are regression coefficients $(\mathrm{i}=1,2,3 \ldots \ldots, 15)$ 
Table.3 Training variables and their assigned values for GFF models

\begin{tabular}{|c|c|}
\hline Training variables & Assigned values for GFF \\
\hline Processing Elements & $2,4,6,8,10$ \\
\hline Activation function & Tanh \\
\hline Learning rule & Delta-Bar-Delta \\
\hline Epoch & 1000 \\
\hline Training threshold & 0.001 \\
\hline
\end{tabular}

Table.4 Statistical Indices for selected GFF models during the testing phase for Chhota Udaipur

\begin{tabular}{|c|c|c|c|c|c|c|c|c|c|}
\hline \multirow{2}{*}{$\begin{array}{c}\text { Model } \\
\text { No. }\end{array}$} & \multirow{2}{*}{$\begin{array}{c}\text { Processing } \\
\text { Element }\end{array}$} & \multicolumn{4}{|c|}{ Training } & \multicolumn{4}{|c|}{ Testing } \\
\hline & & MSE & $\mathbf{r}$ & CE & $\mathbf{R}^{2}$ & MSE & $\mathbf{r}$ & CE & $\mathbf{R}^{2}$ \\
\hline M8 & $(1-6-1)$ & 0.0198 & 0.5810 & 0.3380 & 0.3380 & 0.0002 & 0.9910 & 0.8920 & 0.9810 \\
\hline M8 & $(1-4-1)$ & 0.0197 & 0.5840 & 0.3410 & 0.3410 & 0.0003 & 0.9640 & 0.8250 & 0.9290 \\
\hline M8 & $(1-8-1)$ & 0.0193 & 0.5940 & 0.3530 & 0.3530 & 0.0004 & 0.9110 & 0.7500 & 0.8300 \\
\hline M10 & $(1-2-1)$ & 0.0203 & 0.5660 & 0.3200 & 0.3200 & 0.0007 & 0.8970 & 0.5470 & 0.8050 \\
\hline M9 & $(1-2-1)$ & 0.0199 & 0.5800 & 0.3360 & 0.3360 & 0.0009 & 0.8040 & 0.4640 & 0.6460 \\
\hline M14 & $(1-4-1)$ & 0.0170 & 0.6560 & 0.4300 & 0.4300 & 0.0009 & 0.7810 & 0.4270 & 0.6090 \\
\hline M6 & $(1-6-1)$ & 0.0200 & 0.5860 & 0.3310 & 0.3440 & 0.0008 & 0.7780 & 0.4850 & 0.6050 \\
\hline M11 & $(1-6-1)$ & 0.0215 & 0.5900 & 0.2810 & 0.3480 & 0.0014 & 0.7970 & 0.1470 & 0.6350 \\
\hline M11 & $(1-4-1)$ & 0.0190 & 0.6030 & 0.3640 & 0.3640 & 0.0010 & 0.7710 & 0.3940 & 0.5950 \\
\hline M10 & $(1-4-1)$ & 0.0174 & 0.6460 & 0.4170 & 0.4170 & 0.0013 & 0.7630 & 0.2200 & 0.5820 \\
\hline
\end{tabular}

Table.5 Statistical indices for selected MLR models during testing phase for Chhota Udaipur.

\begin{tabular}{|c|c|c|c|c|c|}
\hline \multirow{2}{*}{$\begin{array}{l}\text { Model } \\
\text { No. }\end{array}$} & \multirow[t]{2}{*}{ Regression equation } & \multicolumn{4}{|c|}{ Statistical index } \\
\hline & & MSE & CE & $\mathbf{r}$ & $\mathbf{R}^{2}$ \\
\hline MLR 15 & $\begin{array}{l}\mathrm{Qt}=213.6775+\left(\mathrm{Tmin}^{*}-2.92753\right)+\left(\mathrm{WS}^{*}{ }_{-}\right. \\
3.73447)+\left(\mathrm{Rt}^{*} 0.991803\right)+\left(\mathrm{Qt}^{*} 1.204708\right)\end{array}$ & 5673.21 & 0.1666 & 0.4082 & 0.1666 \\
\hline MLR 12 & $\begin{array}{c}\mathrm{Qt}=209.9411+\left(\mathrm{Tmax}^{*}-2.97665\right)+\left(\mathrm{Tmin}^{*}-\right. \\
\text { 3.39579) }+(\mathrm{Rt} * 1.207769)\end{array}$ & 5673.97 & 0.1665 & 0.4081 & 0.1665 \\
\hline MLR 13 & $\begin{array}{c}\mathrm{Qt}=160.0035+\left(\mathrm{Tmax}^{*}-3.86126\right)+\left(\mathrm{WS}^{*}-\right. \\
1.35477)+\left(\mathrm{Rt}^{*} 1.16748\right)\end{array}$ & 5693.07 & 0.1637 & 0.4005 & 0.1637 \\
\hline MLR 7 & $\begin{array}{c}\mathrm{Qt}=158.0361+\left(\mathrm{Tmax}^{*}-3.9231\right)+ \\
(\mathrm{Rt} * 1.156284)\end{array}$ & 5694.88 & 0.1634 & 0.4043 & 0.1634 \\
\hline MLR 14 & $\begin{array}{l}\mathrm{Qt}=245.1614+(\mathrm{Tmin} *-914803)+ \\
(\mathrm{WS} * 2.965122)+(\mathrm{Rt} * 1.379027)\end{array}$ & 5763.46 & 0.1534 & 0.3916 & 0.1534 \\
\hline MLR 9 & $\mathrm{Qt}=235.2392+\left(\mathrm{Tmin}^{*}-8.3815\right)+(\mathrm{Rt} * 1.39741)$ & 5770.50 & 0.1523 & 0.3903 & 0.1523 \\
\hline MLR 10 & $\mathrm{Qt}=46.36337+(\mathrm{WS} *-4.85877)+\left(\mathrm{Rt}^{*} 1.462729\right)$ & 5985.08 & 0.1208 & 0.3476 & 0.1208 \\
\hline MLR 4 & $\mathrm{Qt}=32.19349+(\mathrm{Rt} * 1.438534)$ & 6009.34 & 0.1172 & 0.3424 & 0.1172 \\
\hline MLR 11 & $\begin{array}{c}\mathrm{Qt}=221.8175+\left(\mathrm{Tmax}^{*}-5.20962\right)+\left(\mathrm{Tmin}^{*}-\right. \\
0.90881)+(\mathrm{WS} * 2.601608)\end{array}$ & 6159.40 & 0.0952 & 0.3086 & 0.0952 \\
\hline MLR 6 & $\begin{array}{c}\mathrm{Qt}=208.3802+\left(\operatorname{Tmax}^{*}-5.42472\right)+ \\
(\mathrm{WS} * 2.004485)\end{array}$ & 6160.60 & 0.0950 & 0.3083 & 0.0950 \\
\hline
\end{tabular}


Fig.1 Map of Gujarat in India and map of Chhota Udaipur in Gujarat.

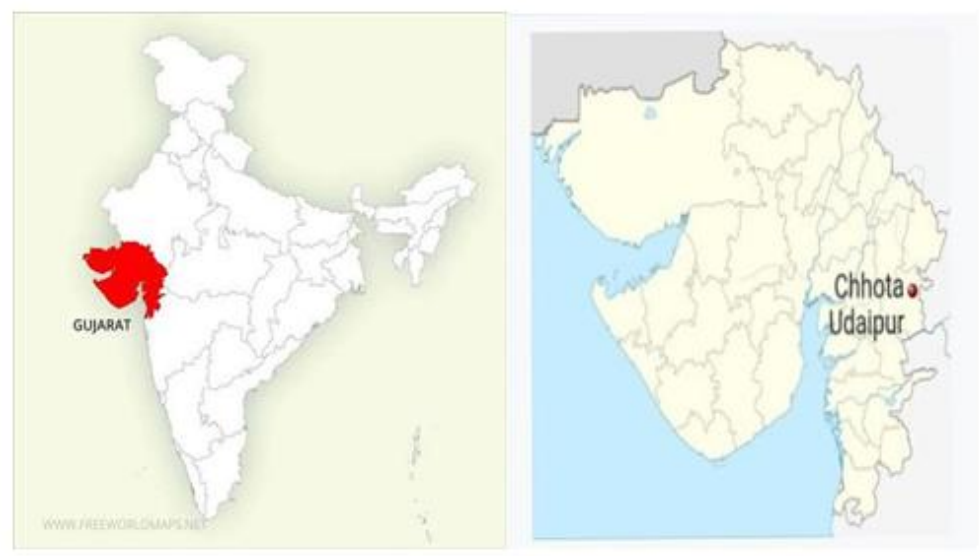

Fig.2 Single Hidden ANN structure

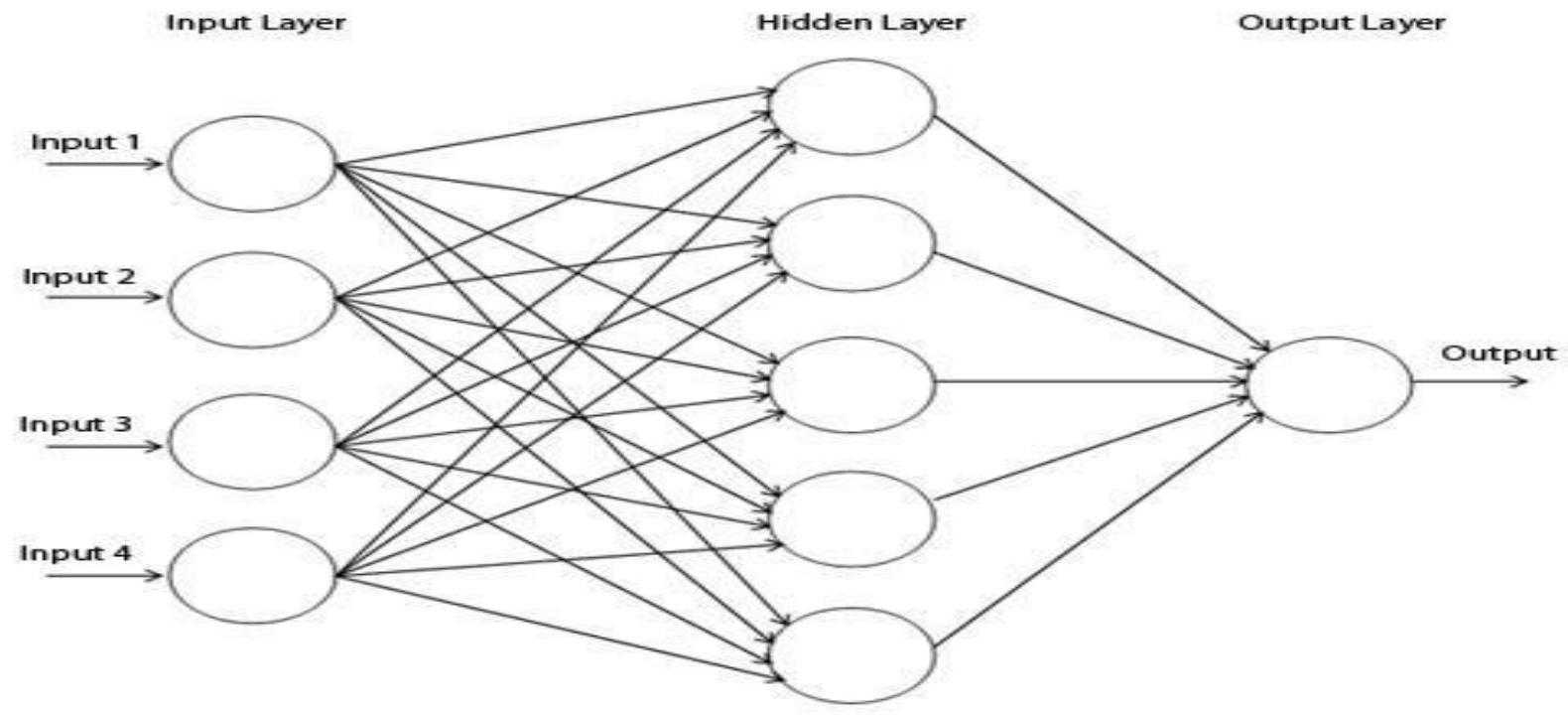

Fig.3 Hyperbolic tangent function.

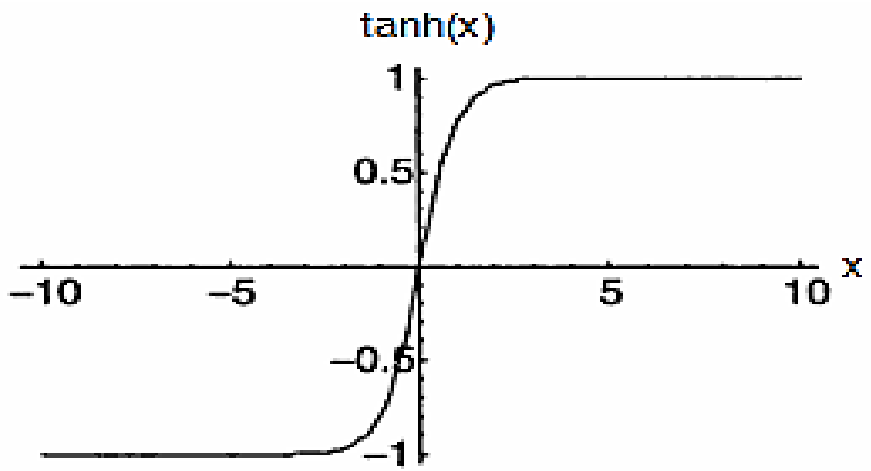


Fig.4 Comparison of observed (Qo) and predicted (Qp) runoff and corresponding scatter plot by GFF -8 (1-6-1) during the testing period
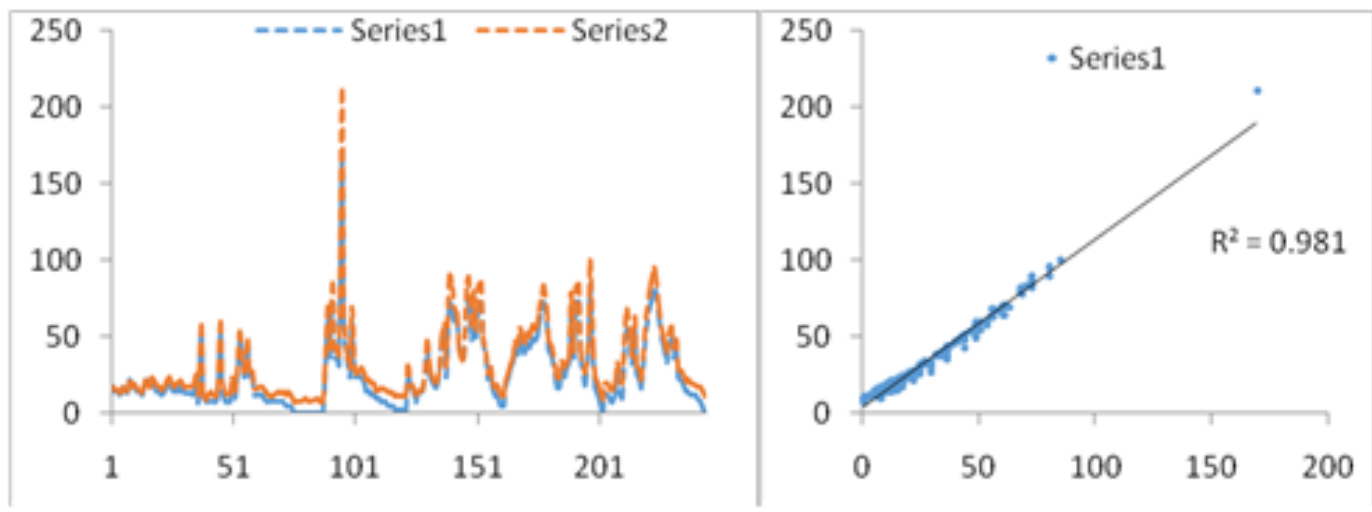

Fig.5 Comparison of observed (Qo) and predicted (Qp) runoff and corresponding scatter plot by MLR-15 during the period

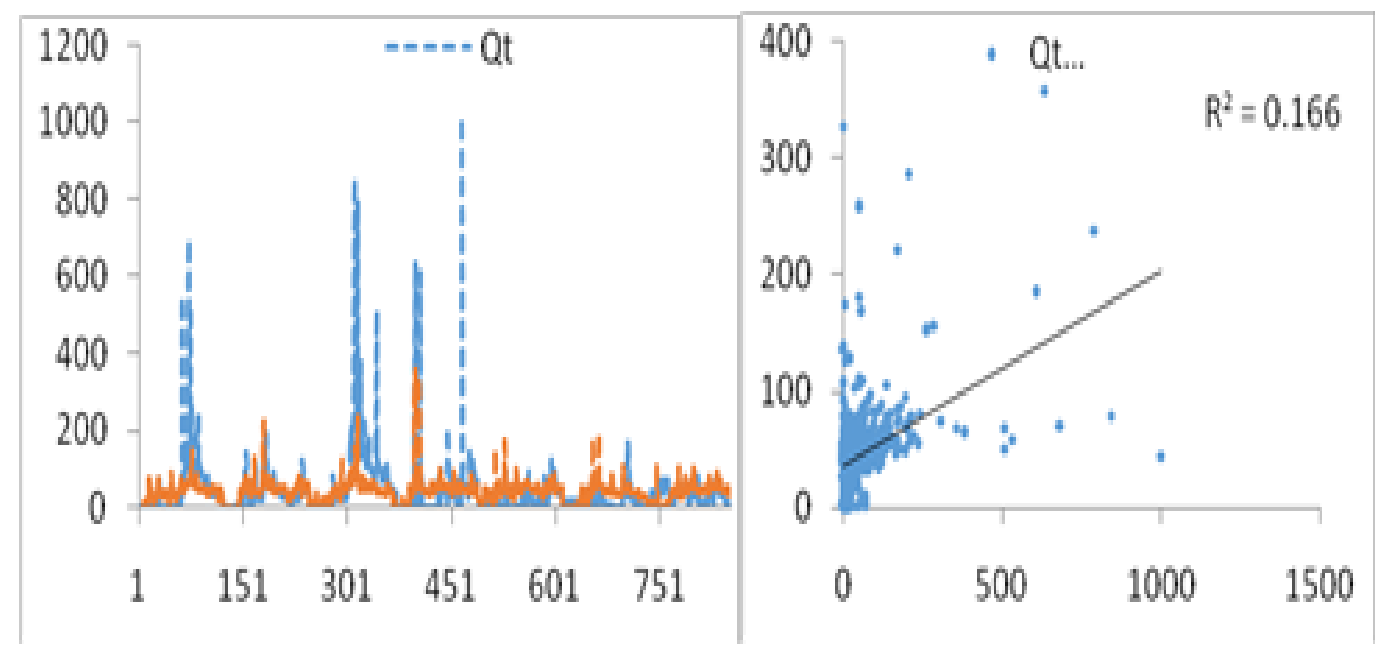

The increased values of $\mathrm{CE}$ and $\mathrm{r}$ by GFF model during testing period indicate good generalization capability of the selected GFF models. On the basis of lower values of MSE (0.0002) and higher CE (0.8920) and $r$ (0.9910) in the testing phase, the GFF 8 (1-61) model was found to be best performing model. Therefore, according to this model, the Runoff can be simulated using the data of the minimum temperature \& wind speed. It was closely followed by GFF- 8 models according to which the Runoff depends on minimum temperature \& wind.

The temporal variation of observed (Qto) and predicted (Qtp) values simulated by the GFF-8 models for the testing period are compared using Rt graph and corresponding scatter plot shown as in Figures. 4 for GFF models. These Rt graphs indicate that all the models. The scatter plot indicates that the simulated and observed runoff during testing or validation 
period match very closely for GFF- 8 models with $\mathrm{R}^{2}$ value of 0.9810

\section{Runoff modelling using MLR}

\section{Regression}

Regression is a linear approach for modelling the relationship between two variables. The dependent variable, " $y$ ", is the quantity we would like to predict (in this case, rental price). We predict the dependent variable using the known value of the independent variable, " $x$ ". the goal of simple linear regression is to create a function that takes the independent variable as input and outputs a prediction for the value of the dependent variable. Remember the algebra class? Since the model is a line, writing it in the form $y=a$ $+b^{*} x$ allows it to be uniquely represented by two parameters: slope (b) and intercept (a)

Linear regression is one of the most popular tools in statistics, and it is frequently used as a predictor for machine learning.

On the basis of the lowest value of MSE and the highest values of $r$ and CE, the MLR-15 model was found to be the best performing model. Therefore, according to MLR-15 model, the current day's runoff depends on minimum temperature, maximum temperature, wind speed and rainfall of current day.

The observed $\left(\mathrm{Q}_{\mathrm{o}}\right)$ and predicted $\left(\mathrm{Q}_{\mathrm{p}}\right)$ runoff simulated by MLR models was compared in the form of runoff graph and scatter-plot as shown in Figs. 5 The runoff graphs indicate that the models under predict the peak runoff as confirmed by the scatter plots also. This study gave clear indication of nonapplicability of the MLR model to simulate runoff for the study watersheds due to low values of $\mathrm{CE}$ and $\mathrm{r}$. In this study, we attempted to forecast the daily runoff on the basis of Generalised Feed Forward (GFF) and Multi
Linear Regression (MLR) techniques for Narmada basin at Chhota Udaipur District Gujrat. Daily weather data were collected.

Fifteen GFF models and MLR were selected based on the performance evaluation indices during the testing period. The following conclusions were drawn from the results in this study:

The results obtained on the basis of statistical indices (MSE, $r$ and $\mathrm{CE}$ ) indicates that the GFF model in general gave consistently better performance than the MLR models.

The GFF model with input of maximum temperature, minimum temperature, wind speed and rainfall was found to be the best for prediction of runoff.

It was clearly evident the Multi Linear Regression Method is not suitable for the dataset under this study.

\section{References}

Bekel, F. G. (2017). Integrated modelling System for multi-objective management of ecosystem services in a watershed. University of Carbondale, United States.

Chavan, P. M. and Ukrande, S. K. (2017) "Comparison of Rainfall-Runoff Model Using ANN and MLR", International Journal of Recent Advances in Engineering \& Technology (IJRAET). 5(1): $2347-2812$.

Chiang, Jie-Lun \& Tsai, Yu-Shiue. (2011). Suspended sediment load estimate using support vector machines in Kaoping river basin. 2011 International Conference on Consumer Electronics, Communications and Networks, CECNet 2011 Proceedings. 10.1109/ CECNET. 2011.5769267.

Dawson, C. \& Wilby, R. (2001). Hydrological Modelling Using Artificial Neural Networks. Progress in Physical Geography 
- PROG PHYS GEOG. 25. 80-108. $10.1177 / 030913330102500104$.

Encephalitis risk zone mapping using remote sensing data: a

Ghumman A. R., Ghazaw Y., Sohail A. R. \& Watanabe K.. (2012). Runoff forecasting by artificial neural network and conventional model. Alexandria Engineering Journal.

Kisi, O. 2005. Suspended sediment estimation using neuro-fuzzy and neural network approaches", Hydrological Sciences Journal, 50(4): 683-696.

Kumar, A., Kumar, A., Ranjan, R. \& Kumar, S. (2012). A rainfall prediction model using artificial neural network. Proceedings IEEE Control and System Graduate Research Colloquium, ICSGRC 2012. 8287.

Litta, A. J., \& Idicula, Sumam \& Mohanty, U C. (2013). Artificial Neural Network Model in Prediction of Meteorological Parameters during Premonsoon Thunderstorms. International Journal of Atmospheric $\quad 2013$. 10.1155/2013/525383.

Malik, A, \& Kumar, A., (2015). Pan evaporation simulation based on daily meteorological data using soft computing techniques and multiple linear regression. Water Resour Manag 29:1859-1872. https://doi.org/10.1007/s11269-015-09150

Mendes, M., Gomes, C., Marques-Quinteiro, P., Lind, P., \& Curral, L. (2016). Promoting learning and innovation in organisations through Complexity Leadership Theory.
Team Performance Management, 22(5/6), 301-309. doi: 10.1108/TPM- 02-20160004

Mishra B, Ghimire B R, Baral D, et al., (2013), Japanese

Mishra, B., Bhoj G., Baral, D., \& Mishra, Y., \& Nagai, M., (2013). Japanese Encephalitis Risk Zone Mapping Using Remote Sensing Data: A Case Study of Mid and Far-Western Part of Nepal. Journal of Remote Sensing \& GIS. 4. 47-55.

Mislan., Haviluddin., Hardwinarto, S., Sumaryono S., \& Marlon A., (2015). Rainfall Monthly Prediction Based on Artificial Neural Network - A Case Study Tenggarong Station, East Kalimantan Indonesia. Procedia Computer Science. 59. 10.1016/j.procs.2015.07.528.

Otair, Mohammed \& Walid, A. Salameh. (2006). Efficient Training of Backpropagation Neural Networks. Neural Network World. 16.

Rumelhart, D., Hinton, G. \& Williams, R. (1986). Learning representations by backpropagating errors. Nature 323, 533-536. https://doi.org/10.1038/323533a0

Tapkin, S., M. Tuncan, O. Arioz, A. Tuncan, and K. Ramyar, Conference for Computer Aided Engineering and System Modeling, 11th FIGES User's Conference, Conference Proceed., Turkey, (September,2006)

Valunjkar, S. \& Patil, Santosh., (2014). Forecasting Of Daily Runoff Using Artificial Neural Networks. International Journal of Civil Engineering and Technology. 5. 13-20.

\section{How to cite this article:}

Shrisht Suman, Vikram Singh, Tushar Rathod and John Wesley, C. 2021. Runoff Modeling using ANN-based Generalized Feed Forward (GFF) and Multi Linear Regression (MLR) Technique for Narmada River Basin, Gujarat. Int.J.Curr.Microbiol.App.Sci. 10(08): 247-257. doi: https://doi.org/10.20546/ijcmas.2021.1008.029 